Research Article

\title{
The Effects of the Dark Triad Traits on the Five Pillars of Positive Psychology: The Moderation Effect of Gender
}

Beata Grabovac ${ }^{\bowtie 1}$ (D) and Jelena Šakotić Kurbalija² (D)

${ }^{1}$ Department of Social Sciences and Humanities, Hungarian Language Teacher Training Faculty, University of Novi Sad, Serbia

2 Department of Psychology, Faculty of Philosophy, University of Novi Sad, Serbia

ABSTRACT

The current study investigated the effects of the Dark Triad traits (Machiavellianism, narcissism, and psychopathy) on mental health indicators from the viewpoint of positive psychology. Additionally, the moderation effect of gender was explored in the context of these relationships. The sample consisted of Hungarian adults from Serbia (439, 54\% women). The participants completed the Short Dark Triad Scale (SD3) and the Mental Health Test (MHT), which is a new measure of mental health that can identify levels of well-being, savoring, creative and executing efficiency, self-regulation, and resilience. Results showed that narcissism positively predicted all mental health indicators, while psychopathy negatively predicted all indicators, except for resilience, with which it showed no significant relationship. Machiavellianism was a positive predictor of savoring, creative and executing efficiency, but a negative predictor of self-regulation and resilience and it had no significant effect on well-being. There was no significant moderation effect of gender.

Keywords: Dark Triad, mental health, positive psychology, gender 
UDC: 159.923.072:159.913

DOI: 10.19090/pp.2021.4. 483-508

Received: 23.09.2021.

Revised: 03.11.2021.

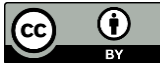

Copyright (c) 2021 The Author(s).

This is an open access article distributed under the terms of the Creative Commons Attribution License, which permits unrestricted use, distribution, and reproduction in any medium, provided the original author and source are credited.

Accepted: 07.12.2021.

Corresponding author email: beata.grabovac@magister.uns.ac.rs 


\section{Introduction}

\section{The Dark Triad of Personality}

Many concepts in psychology can be considered as continuum with positive and negative endpoints and the field of personality is no exception. The so-called Dark Triad encompasses individuals who focus on personal gain, as opposed to light personalities, which refer to individuals that are "good" kind and warm to others (Kaufman et al., 2019). The three members of the above-mentioned dark personalities are Machiavellianism, subclinical narcissism, and subclinical psychopathy (Paulhus \& Williams, 2002), which represent the malevolent and vicious side of human nature. This is mirrored in the fact that risk toward others as well as toward self was positively related to all three Dark Triad members (Dinić et al., 2020).

The Dark Triad traits have shared features referred to as the Dark Core. Jones and Figueredo (2013) proposed the following elements of the Dark Core - interpersonal manipulation and callous affect. A newer candidate for the "heart of darkness" has also emerged in the form of a combination of three antagonistic traits - callousness (as the hallmark of psychopathy), deceitfulness (Machiavellianism), and grandiosity (narcissism), with the callousness facet occupying the central role (Dinić et al., 2021).

Besides a shared Dark Core, each member of the Dark Triad has has unique characteristics. For Machiavellianism, these include amorality, cynicism, a lack of empathy (Bereczkei, 2016), and strategic functioning (Szabó \& Jones, 2019). For narcissism, they are grandiosity and dominance, with feelings of entitlement and superiority (Paulhus \& Williams, 2002). Finally, psychopathy is further characterized by high impulsivity, thrill-seeking, low empathy, lack of remorse (Paulhus \& Williams, 2002). There are welldocumented gender differences in the Dark Triad traits (e.g., Muris et al., 2017), with men consistently showing higher scores on all three traits. 


\section{Mental Health from the Viewpoint of Positive Psychology}

Mental health can be captured through positive and negative psychological constructs. It has various definitions, which can differ in central concepts or content (e.g., whether they refer to mental disorders or merely personal capacities). The World Health Organization (WHO, 2021) defines mental health as "a state of well-being in which an individual realizes his or her own abilities, can cope with the normal stresses of life, can work productively, and is able to make a contribution to his or her community". Keyes and Lopez (2002, pp. 48) view it "as a complete state consisting of (a) the absence of mental illness and (b) the presence of high-level well-being".

From the viewpoint of positive psychology, one of the newest and most detailed definitions has been offered by Vargha and colleagues (2020, pp. 2). They believe that mental health can be described as "well-being on a biological, psychological, societal, and spiritual level and besides this it is a capability to maintain and experience positive states and it is as well associated with the presence of efficient coping and savoring, resilience, and dynamic self-regulation". In sum, it is a sense of being in the right place regarding the present and having a broad psychological capacity to fight against life's adversities. The conception of mental health of Vargha et al. (2020) includes five indicators: well-being, savoring, creative and executing efficiency, self-regulation, resilience.

Nagy (2019) based on the work of other scholars sums up components and main characteristics of well-being or global well-being, which means that the person shows high levels of (1) emotional or subjective, (2) psychological, (3) social, and (4) spiritual well-being: the first signifies the predominance of positive emotions and life satisfaction, the second refers to personal capacity building, growth and independence, the third relates to being well-adjusted to the social world, and the fourth is an optimistic attitude towards the questions of life and death, purpose, and other related concepts. Savoring denotes the "capacity to enjoy life" as well as maintaining and experiencing positive psychological states (Nagy \& Oláh, 2013, pp. 566). Creative and executing efficiency is a personal capability to adaptively change oneself, the 
physical or social situation under heightened circumstances for goal attainment (Oláh, 2005). Self-regulation is the ability to exert control over the functioning of the mind on a cognitive and emotional level and determination in goal attainment (Oláh, 2005). Resilience taps adaptive functioning in the face of adversities, along with mental flexibility or psychological immunity (Vargha et al., 2020). It is grounded in the work of Block and Kremen (1996), who see ego resiliency as a capacity to modify ego control in response to environmental challenges with the goal of maintaining personal balance. Likewise contributing to this foundation are Smith et al. (2008), who define it as the ability to bounce back or recover from stress.

Based on this definition of mental health, Vargha and colleagues (2020) have developed a new measure with the aim of providing an insight into the quality of individuals' everyday functioning, which we utilized in our study. Regarding the Mental Health Test, Vargha et al. (2020) have found a gender difference for savoring, which is higher in women in all age groups and an interaction effect of the age and gender for self-regulation (in women it becomes higher with age in all age groups, while in men it grows just in the category of 26-50 year-olds).

\section{The Dark Triad and Positive Mental Functioning}

Thus far, studies have mainly linked Dark Triad traits to disadvantages in various fields of life: emotional, social, and interpersonal (Aghababaei \& Błachnio, 2015, Jonason et al., 2015, Muris et al, 2017). The results of the metaanalysis conducted by Muris et al. (2017) showed that when the shared variance among Dark Triad traits was controlled, only psychopathy emerged as a significant correlate of various mental health indicators.

Psychopathy correlated negatively with life satisfaction and happiness (or subjective well-being); showed negative zero-order and partial correlations with environmental mastery, personal growth, positive relations with others, purpose in life, and self-acceptance (Aghababaei \& Błachnio, 2015). It negatively predicted hope, emotional and psychological well-being 
(Jonason et al. 2015) and was negatively related to emotionality and selfcontrol (and in one study to well-being) (Petrides et al. 2011). Psychopathy was positively related to problematic functioning in close and social relationships and to risk taking (measuring both harming oneself and others) (Dinić et al. 2020) and negatively predicted life satisfaction, positive affect, and psychological and social well-being (Joshanloo, 2021). A study focusing on psychopathy found it to be negatively related to subjective well-being and positively related to subjective ill-being, which was mirrored in its negative associations with positive affect, happiness, and life satisfaction. On the other hand, the results showed that psychopathy positively correlated with negative affect and depression (Love \& Holder, 2014). Bonfá-Araujo and colleagues (2021) found that psychopathy was positively related to depression and negatively to life satisfaction. Saltoğlu and Irak (2020) found negative associations between primary and secondary psychopathy and life satisfaction and positive relations between primary and secondary psychopathy and stress. They further reported that secondary psychopathy (individuals who commit antisocial acts, have remorse and fear, see Dean et al., 2013) positively correlated with depression and anxiety. Primary psychopathy (individuals who commit antisocial acts, lack empathy and fear, see Dean et al., 2013) was related to more adaptive coping styles than secondary psychopathy. Psychopathy has also been found to be negatively related to self-control (Jonason \& Tost, 2010), but Furtner et al. (2017) found no association between psychopathy and self-leadership (,evaluating one's assumptions, visualizing productive behavior patterns, and pursuing one's goals", pp. 369). It was positively related to anxiety, which can be linked to self-regulation mechanisms (Lyons et al. 2019) and negatively related to resilience (Bagheri Sheykhangafshe et al., 2021; Kun et al. 2021). For psychopathy Muris et al. (2017) state that it is generally characterized by aggression/delinquency, erratic behavior, sex-related issues, socioemotional deficits, poor well-being, interpersonal difficulties, morality problems, and antisocial tactics. In sum, based on previous studies psychopathy is negatively linked to various mental health indicators, including subjective, psychological, social well-being, savoring, self-regulation and resilience. 
Machiavellianism showed a negative correlation with happiness looking at both zero-order and partial correlations; showed negative zeroorder correlations with environmental mastery, personal growth, positive relations with others, purpose in life, and self-acceptance, but the partial correlations were non-significant, except for environmental mastery, with which there was a negative relation (Aghababaei \& Błachnio, 2015). Machiavellianism negatively predicted hope, self-esteem, emotional wellbeing, psychological well-being, and social well-being (Jonason et al. 2015) and was negatively correlated with well-being, emotionality (emotion perception and expression) and self-control (Petrides et al. 2011). It was negatively related to poor subjective well-being, but positively related to risk taking (measuring both harming oneself and others, see Dinić et al. 2020) and negatively predicted life satisfaction, positive affect, and psychological and social well-being (Joshanloo 2021). Although some authors state that Machiavellians have high self-control (e.g., Furtner et al., 2017), others have shown the opposite, finding a negative relation between self-control and Machiavellianism (Shamsudheen et al., 2017) or found inconsistent results negative or no relationship (Jonason \& Tost, 2010). Furtner et al. (2017) found no association between Machiavellianism and self-leadership. Machiavellianism increases the likelihood of mental distress (Lyons et al. 2019), positively predicted negative affect and it related negatively to resilience (Bagheri Sheykhangafshe et al., 2021; Kun et al. 2021). For Machiavellianism, Muris et al. (2017) have drawn a conclusion that a main characteristic of Machiavellianism is that it generally shows interpersonal difficulties and antisocial tactics. This is mirrored in results that show its negative relationship with social well-being (Jonason et al, 2015, Joshanloo, 2021), although social skills are positively related to it (Jonason et al, 2015). Based on the results we might expect that Machiavellianism is related negatively to subjective, psychological and social well-being, savoring, resilience and that relations with self-regulation are inconclusive, based on previous mixed results.

Compared to other Dark Triad members, narcissism correlated positively with life satisfaction and happiness (or subjective well-being); 
showed positive zero-order and partial correlations with psychological wellbeing (Aghababaei \& Błachnio, 2015), positively predicted hope, self-esteem, emotional well-being, psychological well-being, and social well-being (Jonason et al. 2015) and was consistently positively related to well-being and sociability (Petrides et al. 2011). Narcissism also positively predicted life satisfaction, positive affect, and psychological and social well-being (Joshanloo, 2021) and was negatively related to poor subjective well-being, but positively related to risk taking (measuring both harming oneself and others, see Dinić et al. 2020). Narcissism showed significant negative correlation with self-control (Jonason \& Tost, 2010), it aided coping with stressful events (Lyons et al. 2019), and it was positively related to resilience (Bagheri Sheykhangafshe et al., 2021). Results also suggest that the positive relationship between narcissism and resilience was mediated by mental toughness (Kun et al. 2021). Muris et al. (2017) showed that narcissism seems to be the least problematic when taking into account the Dark Triad traits, showing only interpersonal difficulties. In sum, these results have shown that narcissism is positively related to subjective, psychological, social well-being, savoring and resilience and negatively to self-regulation.

Thus, we can conclude that studies focusing on mental health and well-being have used various measures to reveal their connection with the dark traits and have shown that narcissism may be more on the benevolent side and Machiavellianism and psychopathy more on the malicious side of human functioning (e.g., Aghababaei \& Błachnio, 2015; Joshanloo, 2021). To further these inquiries, our research focused on predicting the pattern of five mental health indices from the field of positive psychology using Vargha et al.'s components (2020) based on Dark Triad traits.

Previous research pointed in the direction that gender might moderate the relationships between Dark Triad traits and mental health indicators. Thus, it was shown that empathy significantly correlated with narcissim in women and more strongly than in men; it was strongly negatively correlated with psychopathy in men, but for women this relation was again negative and significant (Jonason et al., 2013). Szabó and Jones (2019) found 
that Machiavellianism was positively related to motor impulsivity, nonplanning, inattention and overall impulsivity in women and positively related to motor impulsivity and negatively to non-planning in men, while its association with overall impulsivity was non-significant in this subgroup. In women narcissism was positively related to motor impulsivity and negatively to non-planning and there were no significant relations with overall impulsivity, while in the group of men narcissism was negatively related to non-planning, inattention and overall impulsivity. Psychopathy showed a positive relation with all kinds of impulsivity and overall impulsivity both in men and women.

However, Bonfá-Araujo et al. (2021) found no moderating effect of gender between Dark Triad traits and depression and life satisfaction. Thus, in our study we also wanted to explore the moderation effect of gender in prediction of mental health based on Dark Triad traits. Taking into account previous research, we hypothesized that:

1. Machiavellianism will show a positive effect on creative and executing efficiency (e.g., Muris et al., 2017) and it will have a negative effect on well-being (Aghababaei \& Błachnio, 2015), savoring (Jonason et al, 2015), self-regulation (Petrides et al., 2011) and resilience (Kun et al., 2021).

2. Narcissism would positively predict well-being (Aghababaei \& Błachnio, 2015), savoring (Bonfá-Araujo et al., 2021), creative and executing efficiency (e.g., Muris et al., 2017) and resilience (Kun et al., 2021). It would show a negative relation with self-regulation (Jonason \& Tost, 2010).

3. Psychopathy would negatively predict all five mental health indicators: well-being (Aghababaei \& Błachnio, 2015), savoring (Love \& Holder, 2014), creative and executing efficiency (Muris et al., 2017), self-regulation (Jonason \& Tost, 2010) and resilience (Kun et al., 2021).

4. We expected gender to have a moderation role on the effects of the Dark Triad traits on mental health indicators. Previous studies showed 
gender differences related to the dark traits and variables of emotional functioning and self-regulation, etc. (Jonason et al., 2013, Szabó \& Jones, 2019). Although there are no many studies in which the moderation role of gender was explored, in the existing ones the moderation role of gender was confirmed, with significant or stronger relations between dark traits and mental health indicators among men or showing gender-based/biased patterns.

\section{Method}

\section{Sample}

The sample included 439 Hungarian adults (54\% women), aged 18-72 years $(M=26.07, S D=10.79)$, from Serbia and the research was conducted in the Hungarian language. The majority (51.9\%) were students or finished faculty. Students from the Hungarian Language Teacher Training Faculty at the University of Novi Sad were given course credit for their participation and they were given the task to recruit other adult participants - two men and two women each. Data were collected anonymously via an online form on the Google Forms platform. An informed consent was obtained from all participants. The Institutional Review Board of the Hungarian Language Teacher Training Faculty in Subotica, University of Novi Sad (202105192BGBDJŠ), approved the study.

\section{Instruments}

\section{The Short Dark Triad Scale (SD3)}

The Short Dark Triad Scale (SD3; Jones \& Paulhus, 2014, for Hungarian adaptation see Szabó et al., 2021). SD3 has 27 items measuring Dark Triad traits (Machiavellianism, narcissism, and psychopathy), per 9 items each. Participants give answers on a 5-point Likert-type scale (1 - Strongly disagree to 5 - Strongly agree). 
The Mental Health Test (MHT)

The Mental Health Test (MHT; Vargha et al., 2020). MHT was developed in Hungarian and has 17 items distributed in five subscales: wellbeing (3 items, e.g., "In my everyday life there is significantly more happiness than sadness.") measuring emotional, psychological, social, and spiritual wellbeing; savoring ( 3 items, e.g., "I like to store memories of happy times, to recall them afterwards.") measuring making, maintaining, and intensifying positive experiences; creative and executing efficiency (5 items, e.g., "Other people also think that I am a good problem-solver.") measuring ability to cope in hardship and keep fighting for personal goals; self-regulation (3 items, e.g., "I become impatient easily.") measuring emotion- and self-control; and resilience (3 items, , e.g., "After hard times my recovery is fast.") measuring successful adaptation to stressful events and recovery. Answers are given on a 6-point Likert-type scale (1 - Not typical of me at all to 6 - Totally typical of me for the first 17 items and 1 - Not at all to 6 - Totally for the 18th item). Since there is no previous model testing, in this research model fit was tested via confirmatory factor analysis. The model fit for the proposed five-factor model with correlated factors was acceptable, except for $T L 1:$ MLR $\chi 2(109)=$ 259.67, $p<.001 ; C F /=.90 ; T L I=.88, S R M R=.06 ; R M S E A=.06$. Descriptives and Cronbach's alphas for all scales are given in Table 1.

\section{Statistical Analysis}

We present descriptive statistics, followed by intercorrelations between the variables, gender differences on mental health indicators using t-tests, and the results of hierarchical regression analyses. The goal of the latter analyses was to test the moderation role of gender in prediction of mental health based on Dark Triad traits. After the standardization of the predictor variables, we created three new variables related to interaction effects, which were multiplied by the predictor and moderator variables (which were coded as $0=$ men and $1=$ women). In the first step Dark Triad traits were entered, in the second - gender, and in the third - interactions 
between Dark Triad traits and gender. Analyses were calculated for each mental health indicators, separately. Data was analyzed using IBM SPSS 19 (IBM Corporation, 2010).

\section{Results}

\section{Descriptive Statistics and Correlations}

The values for skewness and kurtosis were in a range from -2 and +2 (Table 1), which is considered acceptable in order to prove a normal univariate distribution (George \& Mallery, 2010). All alpha reliabilities are adequate, given the number of items.

\section{Table 1}

Descriptive Statistics and Cronbach's Alpha Coefficients of the Used Scales

\begin{tabular}{|c|c|c|c|c|c|c|}
\hline Insturments & Scales & $M$ & $S D$ & Sk & Ku & $\begin{array}{c}\text { Cronbach's } \\
\alpha\end{array}$ \\
\hline \multirow{3}{*}{$\begin{array}{l}\text { Short Dark } \\
\text { Triad }\end{array}$} & Machiavellianism & 3.35 & 0.75 & -0.07 & -0.29 & .77 \\
\hline & Narcissism & 2.80 & 0.70 & 0.27 & -0.04 & .72 \\
\hline & Psychopathy & 2.42 & 0.77 & 0.26 & -0.48 & .76 \\
\hline \multirow{5}{*}{$\begin{array}{l}\text { Mental } \\
\text { Health Test }\end{array}$} & Well-being & 4.51 & 1.02 & -0.62 & 0.16 & .71 \\
\hline & Savoring & 4.83 & 0.99 & -0.77 & -0.01 & .71 \\
\hline & $\begin{array}{l}\text { Creative and } \\
\text { executing } \\
\text { efficiency }\end{array}$ & 4.43 & 0.82 & -0.23 & -0.17 & .82 \\
\hline & Self-regulation & 3.07 & 1.11 & 0.11 & -0.36 & .65 \\
\hline & Resilience & 3.52 & 1.11 & -0.10 & -0.28 & .67 \\
\hline
\end{tabular}

Correlations between the Dark Triad traits and mental health indicators were as follows: Machiavellianism showed a small positive correlation with creative and executing efficiency and small negative associations with self-regulation and resilience; narcissism showed a moderate positive correlation with creative and executing efficiency and small positive correlations with well-being, savoring, and resilience; and 
psychopathy showed a moderate negative correlation with self-regulation, small negative correlation with well-being and savoring, and a small positive correlation with creative and executing efficiency (Table 2). Among the Dark Triad traits, psychopathy and Machiavellianism showed higher correlations, while among mental health indicators, well-being and resilience showed higher correlations compared to the rest of the correlations.

\section{Table 2}

Intercorrelations between the Dark Triad Traits and indicators of Mental Health

\begin{tabular}{|c|c|c|c|c|c|c|c|c|}
\hline & 1. & 2. & 3. & 4. & 5. & 6. & 7. & 8. \\
\hline 1. Machiavellianism & 1 & & & & & & & \\
\hline 2. Narcissism & $.36^{\star \star \star}$ & 1 & & & & & & \\
\hline 3. Psychopathy & $.55^{\star \star \star}$ & $.49^{\star \star \star}$ & 1 & & & & & \\
\hline 4. Well-being & -.07 & $.13^{*}$ & $-.14^{\star \star \star}$ & 1 & & & & \\
\hline 5. Savoring & .06 & $.12^{*}$ & $-.11^{*}$ & $.34^{\star \star \star}$ & 1 & & & \\
\hline $\begin{array}{l}\text { 6. Creative and } \\
\text { executing efficiency }\end{array}$ & $.22^{\star \star \star}$ & $.39^{\star \star \star}$ & $.12^{\star}$ & $.38^{\star \star \star}$ & $.38^{* * *}$ & 1 & & \\
\hline 7. Self-regulation & $-.28^{\star \star \star}$ & -.04 & $-.34^{* \star \star}$ & $.13^{*}$ & -.02 & .01 & 1 & \\
\hline 8. Resilience & $-.11^{\star}$ & $.14^{\star \star *}$ & -.02 & $.48^{\star \star \star}$ & $.14^{\star \star}$ & $.24^{\star \star \star}$ & $.24^{\star \star \star}$ & 1 \\
\hline
\end{tabular}

Note: ${ }^{*} p<.05 ;{ }^{* \star} p<.01 ;{ }^{* \star *} p<.001$.

\section{Gender Differences on Dark Triad traits and Mental Health} Indicators

Significant differences were found in savoring, self-regulation, and resilience, savoring was higher in women and self-regulation and resilience were higher in men (Table 3), all showing small effect sizes. Gender differences for Machiavellianism, narcissism and psychopathy were also significant; all of them were higher in males. Machiavellianism and narcissism showed small effect sizes, while psychopathy medium. 


\section{Table 3}

Gender differences in Dark Triad traits and Mental Health Indicators

\begin{tabular}{lcccccc}
\hline Scale & Gender & $M$ & $S D$ & $t(437)$ & $p$ & $d$ \\
\hline \multirow{2}{*}{ Machiavellianism } & men & 3.45 & .75 & 2.39 & .017 & 0.24 \\
& women & 3.27 & .75 & & & \\
Narcissism & men & 2.92 & .68 & 3.39 & .001 & 0.33 \\
& women & 2.69 & .70 & & & \\
Psychopathy & men & 2.63 & .74 & 5.38 & .000 & 0.51 \\
& women & 2.25 & .76 & & & \\
Well-being & men & 4.49 & 1.01 & & & \\
Savoring & women & 4.54 & 1.02 & & & \\
& men & 4.67 & 1.00 & -3.20 & .001 & -0.31 \\
Creative and executing efficiency & women & 4.97 & .96 & & & \\
& men & 4.43 & .87 & & & \\
Self-regulation & men & 4.43 & .78 & & & \\
& men & 3.20 & 1.14 & 2.25 & .025 & 0.22 \\
Resilience & women & 2.96 & 1.08 & & & \\
& men & 3.69 & 1.11 & 3.02 & .003 & 0.28 \\
\hline
\end{tabular}

Effects of the Dark Triad Traits on Mental Health Indicators: Gender Moderation Effect

Results of the hierarchical regression analyses showed that in the first step, the Dark Triad traits explained $7 \%$ of the variance of well-being and savoring, $18 \%$ of the variance of creative and executing efficiency, $15 \%$ of the variance of self-regulation and $5 \%$ of the variance for resilience. Machiavellianism positively predicted savoring, creative and executing efficiency, negatively self-regulation and resilience and with well-being, there was no significant relation. Narcissism positively predicted all mental health indicators, while psychopathy negatively predicted all but resilience with which showed no significant relation. The change of explained variance was significant after introducing gender in prediction of savoring, self-regulation, 
and resilience. Although there was no significant change of explained variance when interactions were added, there was significant interaction between Machiavellianism and gender in the prediction of well-being, but the results of simple slope analyses did not reach statistical significance.

\section{Table 4}

Results of the Hierarchical Regression Analysis: Prediction of Mental Health Indicators based on Dark Triad traits with Gender as a Moderator

\begin{tabular}{|c|c|c|c|}
\hline Criterion variable: Well-being & $\begin{array}{l}\text { Step } 1 \\
\beta\end{array}$ & $\begin{array}{l}\text { Step } 2 \\
\beta\end{array}$ & $\begin{array}{l}\text { Step } 3 \\
\beta\end{array}$ \\
\hline Machiavellianism & -.02 & -.02 & .10 \\
\hline Narcissism & $.26^{\star \star \star}$ & $.26^{\star \star \star}$ & $.25^{\star \star \star}$ \\
\hline Psychopathy & $-.26^{\star * \star}$ & $-.26^{\star \star \star}$ & $-.37^{\star * *}$ \\
\hline gender & & .00 & .00 \\
\hline gender x Machiavellianism & & & $-.24^{\star}$ \\
\hline gender x narcissism & & & .03 \\
\hline \multirow[t]{3}{*}{ gender x psychopathy } & & & .21 \\
\hline & $R=.27^{\star * *}$ & $R=.27^{\star * *}$ & $R=.29^{* * *}$ \\
\hline & $\Delta R^{2}=.07$ & $\Delta R^{2}=.00$ & $\Delta R^{2}=.01$ \\
\hline Criterion variable: Savoring & $\beta$ & $\beta$ & $\beta$ \\
\hline Machiavellianism & $.14^{\star}$ & $.14^{\star}$ & .10 \\
\hline narcissism & $.21^{\star \star \star}$ & $.22^{\star \star \star}$ & $.26^{\star \star \star}$ \\
\hline psychopathy & $-.29 * * \star$ & $-.26^{\star \star \star}$ & $-.21^{\star}$ \\
\hline gender & & $.28^{\star \star}$ & $.28^{\star \star}$ \\
\hline gender x Machiavellianism & & & .08 \\
\hline gender x narcissism & & & -.07 \\
\hline \multirow[t]{3}{*}{ gender x psychopathy } & & & -.09 \\
\hline & $R=.26^{\star \star \star}$ & $R=.29^{\star * *}$ & $R=.29^{\star \star *}$ \\
\hline & $\Delta R^{2}=.06$ & $\Delta R^{2}=.02$ & $\Delta R^{2}=.01$ \\
\hline $\begin{array}{l}\text { Criterion variable: Creative and executing } \\
\text { efficiency }\end{array}$ & $\beta$ & $\beta$ & $\beta$ \\
\hline Machiavellianism & $.16^{\star \star \star}$ & $.16^{\star * \star}$ & $.21^{\star}$ \\
\hline narcissism & $.42^{\star \star \star}$ & $.43^{\star \star \star}$ & $.51^{\star \star \star}$ \\
\hline psychopathy & $-.18^{\star \star *}$ & $-.17^{\star \star \star}$ & $-.28^{* * *}$ \\
\hline gender & & .09 & .08 \\
\hline
\end{tabular}




\begin{tabular}{|c|c|c|c|}
\hline \multirow{3}{*}{$\begin{array}{l}\text { gender x Machiavellianism } \\
\text { gender x narcissism } \\
\text { gender x psychopathy }\end{array}$} & & & -.09 \\
\hline & & & -.16 \\
\hline & & & .21 \\
\hline & $R=.43^{* * *}$ & $R=.43^{\star \star \star}$ & $R=.44^{\star \star *} ;$ \\
\hline & $\Delta R^{2}=.18$ & $\Delta R^{2}=.00$ & $\Delta R^{2}=.01$ \\
\hline Criterion variable: Self-regulation & $\beta$ & $\beta$ & $\beta$ \\
\hline Machiavellianism & $-.16^{\star \star \star}$ & $-.15^{*}$ & -.09 \\
\hline narcissism & $.18^{\star \star \star}$ & $.17^{\star \star \star}$ & $.16^{\star}$ \\
\hline psychopathy & $-.35^{\star \star \star}$ & $-.39 * \star \star$ & $-.46^{\star \star \star}$ \\
\hline gender & & $-.39 * \star \star$ & $-.39 * \star \star$ \\
\hline gender x Machiavellianism & & & -.11 \\
\hline gender $x$ narcissism & & & .03 \\
\hline gender x psychopathy & & & .14 \\
\hline & $R=.39^{* \star *}$ & $R=.43^{\star \star *}$ & $R=.44^{\star \star *}$; \\
\hline & $\Delta R^{2}=.15$ & $\Delta R^{2}=.04$ & $\Delta R^{2}=.00$ \\
\hline Criterion variable: Resilience & $\beta$ & $\beta$ & $\beta$ \\
\hline Machiavellianism & $-.17^{\star \star \star}$ & $-.16^{\star \star \star}$ & .08 \\
\hline narcissism & $.21^{\star \star \star}$ & $.20^{\star \star \star}$ & $.21^{\star \star \star}$ \\
\hline psychopathy & -.03 & -.06 & -.17 \\
\hline gender & & 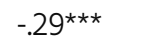 & $-.29 * \star$ \\
\hline gender x Machiavellianism & & & -.17 \\
\hline gender x narcissism & & & -.01 \\
\hline gender x psychopathy & & & .20 \\
\hline & $R=.22^{\star * *}$ & $R=.26^{\star \star \star}$ & $R=.27^{\star \star \star}$ \\
\hline & $\Delta R^{2}=.05$ & $\Delta R^{2}=.02$ & $\Delta R^{2}=.01$ \\
\hline
\end{tabular}

Note: ${ }^{*} p<.05 ;{ }^{* *} p<.01 ;{ }^{* *} p<.001$

\section{Discussion}

The main aim of this study was to reveal the effects of the Dark Triad on mental capacities and strengths using gender as a moderator variable. In other words, we wanted to reveal how Machiavellianism, narcissism, and psychopathy predict well-being, savoring, creative and executing efficiency, self-regulation, and resilience and determine whether gender moderates these relationships. 
As this was the first use of the Mental Health Test in Serbia, we tested gender differences on the Mental Health Test and intercorrelations between the subscales to identify distinct patterns and potential overlaps between the results from Hungary and Serbia. In our study, the subscales of the Mental Health Test showed some significant positive associations, with the highest correlation between well-being and resilience. Conversely, Vargha et al. (2020) found the strongest correlation between well-being and creative and executing efficiency, which was the second strongest association in our study. It should be noted that in our research, creative and executing efficiency and savoring had the same strength of correlation. Regarding the Mental Health Test, we further found that savoring was higher in women and self-regulation and resilience were more characteristic of men. These results do not entirely overlap with the findings reported by Vargha et al. (2020). One explanation for our result about savoring might stem from social gender role differences, women taking the caretaker role (and thus being more emotional) in most families, and additionally differences related to the usage of savoring strategies and personal beliefs about it (see Kim \& Bryant, 2017). In previous studies more frequent use of self-regulation strategies was found in women, which is not in line with our results, but it has been previously emphasized that there is a need for studies that would clarify how men regulate their emotions (Nolen-Hoeksema, 2012).

Regarding our main aim, the first hypothesis about Machiavellianism was partially supported by our findings. Machiavellianism showed the most eclectic picture. Although we expected to find a negative effect, Machiavellianism showed no effect on well-being and this might point to a methodological aspect: more fine-grained measures of well-being should be used. Machiavellianism had a positive effect on savoring, which is in opposition with our hypothesis and previous research results (e.g., Jonason et al., 2015, Joshanloo et al., 2021). Concretely, it is in odds with a previous study, which found that it is connected to alexithymia (Wastell \& Booth, 2003), so this aspect should be also further studied in detail, e.g. revealing strategies that Machiavellians use for enhancing positive moods. We did find a positive 
effect of Machiavellianism on creative and executing efficiency, which can be explained with their emphasized desire for status and power. A negative effect on self-regulation was also found, which has been previously connected to fast life strategy, exploitive, short term and antagonist social strategy (Jonason \& Tost, 2010). Machiavellianism had a negative effect on resilience, which is in line with our hypothesis and the results of Kun et al. (2021). The latter two results are in line with a previous study, which inform about a passive (Machiavellianism and psychopathy) and active coping with stressful situations (narcissism, see Birkás et al., 2016), but not in line with the deliberate nature of Machiavellianism (Jonason et al., 2015).

The second hypothesis about narcissism was confirmed in four aspects out of five. Narcissism showed positive effects on all aspects of mental health measured in this study, so the positive relation with selfregulation is not in accordance with our hypothesis. Van Groningen et al. (2021) believe that grandiose narcissism could be a buffer against adversities, because it is associated with self-aggrandizement and an exaggerated positive sense of self, low self-criticism and high self-esteem; the advantageous effects of a broad social network and good social skills; flexible coping mechanisms and emotional stability. Based on our findings, some authors may conclude that narcissism may have beneficial effects on personal functioning, that it represents the "lighter" side of the dark personality traits (Aghababaei \& Błachnio 2015), and even that it may potentially serve as a buffer between Machiavellianism/psychopathy and well-being (Van Groningen et al., 2021).

However, we must not overlook the fact that the main characteristics of narcissism are selfishness and self-centeredness (Christie \& Geis, 1970, Jambrešić et al., 2020) and low agreeableness (Blötner et al., 2021; Jonason et al., 2009), which all implicate a different personal and interpersonal functioning of the narcissistic individuals compared to people with low dark traits. A similar pattern of discrepancy between the results of quantitative research and underlying processes that lead to them may be observed in the relationship between attachment avoidance, self-esteem and self-efficacy 
(Shaver et al., 2017). One should also bear in mind that attachment avoidance is associated with the grandiose type of narcissism, which includes both selfpraise and denial of weaknesses (Pincus \& Roche, 2011). Therefore, we may also assume that qualitative differences exist in the nature of mental health and well-being indicators between people with high narcissism and light personalities or people with low or no dark traits, which should be examined further.

The third hypothesis about psychopathy was confirmed for four indicators of mental health, the only discrepancy was found for resilience, which was not predicted significantly by psychopathy. Low-quality interpersonal relationships or low emotional intelligence (Love \& Holder, 2014) can account for some difficulties that people with subclinical psychopathy face. Van Groningen et al. (2021) think that the negative relationship between psychopathy and well-being can be explained through the usage of socially aversive tactics, which eventually lead to overt or covert social rejection of these individuals. We did not find any correlation with resilience, unlike Kun et al. (2021), who reported a negative correlation between psychopathy and resilience, which should be further tested measuring different kinds of psychopathy and resilient behavior. Psychopathy is negatively connected to agreeableness, positively to lack of fairness, sincerity and negative psychosocial outcomes (Muris et al., 2017). These individuals are living by fast life strategy. Therefore, we can assume that they have constant difficulties at the level of interpersonal relations in private and professional life, which permeate and have a detrimental effect on all five pillars of mental health.

The fourth hypothesis about the presence of a moderation effect of gender was not confirmed. However, results are line with Bonfá-Araujo et al. (2021), which showed no significant moderation role of gender in the relationships between the Dark Triad traits and depression and life satisfaction. The authors see one explanation for this in the simpler latent structure of the Short Dark Triad Scale than other measures of the dark traits, 
as it does not cover all kinds, aspects and facets of the dark traits. Another weakness is that the sample of Bonfá-Araujo et al. (2021) consisted mainly of women, so they cannot draw firm conclusions about the effects of gender. Our results could be also refined by using more detailed measures of the Dark Triad and the five indicators of mental health. As we have previously highlighted, Machiavellianism should be further studied in relation to wellbeing measures, separately test the four kinds (emotional or subjective, psychological, social, and spiritual well-being), to get a full picture gender could be added as a moderator variable.

The obtained results indicate that psychopathy has a negative effect on mental health, while narcissism may have beneficial effects on personal level. Machiavellianism might be somewhere in the middle, but further inquiries are needed to pinpoint the most salient advantages and shortcomings of these individuals in personal functioning.

The main limitation of this study is that we used self-report questionnaires. It would be beneficial to include behavioral measures (e.g., emotion recognition using pictorial stimuli, stories depicting social-dilemma situations) in future research. Likewise, future studies could use samples that are more diverse in terms of sociodemographic variables and measures that differentiate between the subdimensions of Dark Triad traits (e.g., primary and secondary psychopathy).

The key contribution of this study compared to previous knowledge is that it offers fresh insights concerning three points. First, it adopted the viewpoint of positive psychology to measure the effects of the Dark Triad on several aspects of mental health that have not been studied so far. Second, it utilized the newly developed Mental Health Test from Hungary in Serbia. Finally, there are few studies exploring the moderation effects of gender in the Dark Triad literature, so our work has also added findings to this line of inquiry.

The study has practical implications for improving mental health and personal capacities of Machiavellistic individuals and persons with subclinical psychopathy. Education and trainings targeting positive emotions and 
affective states should be implemented. Likewise, assistance in the development of social skills, coping, and self-regulation strategies is also necessary to raise the level of their successful everyday functioning.

\section{Funding}

This work was supported by the Délvidékért „Kiss” Alapítvány, 2021 (Hungary, Budapest).

\section{Conflict of interest}

We have no conflicts of interest to disclose.

Data availability statement

For further details on data, contact the authors of the manuscript.

\section{References}

Aghababaei, N., \& Błachnio, A. (2015). Well-being and the Dark Triad. Personality and Individual Differences, 86, 365-368.

\section{https://doi.org/10.1016/j.paid.2015.06.043}

Bagheri Sheykhangafshe, F., Abolghasemi, A., \& Kafi Masouleh, S. M. (2021).

Predicting Resilience Based on Dark Triad Personality and Psychological

Wellbeing in Athletes Students. Journal of Arak University of Medical

Sciences, 24(2), 230-245. https://doi.org/10.32598/jams.24.2.6151.1

Bereczkei, T. (2016). Machiavellizmus. A megtévesztés pszichológiája. Budapest:

Typotex.

Birkás, B., Gács, B., \& Csathó, Á. (2016). Keep calm and don't worry: Different Dark Triad traits predict distinct coping preferences. Personality and Individual Differences, 88, 134-138.

\section{https://doi.org/10.1016/j.paid.2015.09.007}

Block, J., \& Kremen, A. M. (1996). IQ and ego-resiliency: conceptual and empirical connections and separateness. Journal of personality and social psychology, 70(2), 349-361. https://doi.org/10.1037/0022-3514.70.2.349 
Blötner, C., Steinmayr, R., \& Bergold, S. (2021). Malicious mind readers? A metaanalysis on Machiavellianism and cognitive and affective empathy. Personality and Individual Differences, 181, 1-34.

https://doi.org/10.31234/osf.io/5fvwr

Bonfá-Araujo, B., Lima-Costa, A. R., Baptista, M. N., \& Hauck-Filho, N. (2021).

Depressed or satisfied? The relationship between the dark triad traits, depression, and life satisfaction. Current Psychology, 1-8. https://doi.org/10.1007/s12144-021-01726-3

Christie, R., \& Geis, F.L. (1970). Studies in Machiavellianism. San Diego, CA: Academic Press. https://doi.org/10.1016/B978-0-12-174450-2.50006-3

Dean, A. C., Altstein, L. L., Berman, M. E., Constans, J. I., Sugar, C. A., \& McCloskey, M. S. (2013). Secondary psychopathy, but not primary psychopathy, is associated with risky decision-making in noninstitutionalized young adults. Personality and individual differences, 54(2), 272-277.

https://doi.org/10.1016/j.paid.2012.09.009

Dinić, B. M., Sadiković, S., \& Wertag, A. (2020). Factor mixture analysis of the Dark Triad and Dark Tetrad: Could sadism make a difference? Journal of Individual Differences, 42(2), 74-83. https://doi.org/10.1027/1614$\underline{0001 / a 000331}$

Dinić, B. M., Wertag, A., Sokolovska, V., \& Tomašević, A. (2021). The good, the bad, and the ugly: Revisiting the Dark Core. Current Psychology, 1-13.

https://doi.org/10.1007/s12144-021-01829-x

Furtner, M. R., Maran, T., \& Rauthmann, J. F. (2017). Dark leadership: The role of leaders' dark triad personality traits. In Clark, M. G., \& Gruber, C. W. (Eds.). Leader Development Deconstructed, Springer, 75-99.

https://doi.org/10.1007/978-3-319-64740-1_4

George, D. \& Mallery, M. (2010). SPSS for Windows Step by Step: A Simple Guide and Reference, 17.0 update (10a ed.), Boston: Pearson.

IBM Corporation (2010). IBM SPSS Statistics for Windows, Version 19.0. Armonk, NY: IBM Corporation. 
Jambrešić, I., Humer, J. T., \& Čikeš, A. B. (2020). Varanje u akademskom okruženju uloga mračnih osobina ličnosti, stavova o varanju i moralnog rasuđivanja. Primenjena psihologija, 13(2), 243-262.

https://doi.org/10.19090/pp.2020.2.243-262

Jonason, P. K., \& Tost, J. (2010). I just cannot control myself: The Dark Triad and self-control. Personality and Individual differences, 49(6), 611-615.

https://doi.org/10.1016/.jpaid.2010.05.031

Jonason, P. K., Baughman, H. M., Carter, G. L., \& Parker, P. (2015). Dorian Gray without his portrait: Psychological, social, and physical health costs associated with the Dark Triad. Personality and Individual

Differences, 78, 5-13. https://doi.org/10.1016/j.paid.2015.01.008

Jonason, P. K., Li, N. P., Webster, G. D., Schmitt, D. P. (2009). The Dark Triad:

Facilitating a short-term mating strategy in men. European journal of personality, 23(1), 5-18. https://doi.org/10.1002/per.698

Jonason, P. K., Lyons, M., Bethell, E. J., \& Ross, R. (2013). Different routes to limited empathy in the sexes: Examining the links between the Dark Triad and empathy. Personality and Individual Differences, 54, 572-576.

https://doi.org/10.1016/j.paid.2012.11.009

Jones, D. N., \& Figueredo, A. J. (2013). The core of darkness: Uncovering the heart of the Dark Triad. European Journal of Personality, 2766), 521-531. https://doi.org/10.1002/per.1893

Jones, D. N., \& Paulhus, D. L. (2014). Introducing the short dark triad (SD3) a brief measure of dark personality traits. Assessment, 27(1), 28-41. https://doi.org/10.1177/1073191113514105

Joshanloo, M. (2021). Conceptions of Happiness Mediate the Relationship Between the Dark Triad and Well-Being. Frontiers in psychology, 12, 1711, 1-9. https://doi.org/10.3389/fpsyg.2021.643351

Kaufman, S. B., Yaden, D. B., Hyde, E., \& Tsukayama, E. (2019). The light vs. dark triad of personality: Contrasting two very different profiles of human 
nature. Frontiers in psychology, 10:467, 1-26.

\section{https://doi.org/10.3389/fpsyg.2019.00467}

Keyes, C. L. M. \& Lopez, S. J. (2002). Toward a Science of Mental Health. Positive directions in Diagnosis and Interventions. In Snyder, C. R., \& Lopez, S. J. (Eds.). Handbook of Positive Psychology, (pp. 45-59.). Oxford Press.

Kim, S., \& Bryant, F. B. (2017). The influence of gender and cultural values on savoring in Korean undergraduates. International Journal of Well-being, 7(2), 43-63. https://doi.org/10.5502/ijw.v7i2.598

Kun, Á., Szabó, Zs. P., \& Balogh, E. B. The bright side of the Dark Triad leaders: The relationship between dark personality traits, mental toughness, resilience, and character strengths. Retrieved October 19, 2021 from: https://www.academia.edu/41511317/The_bright_side_of_the_Dark_Tria d_leaders_The_relationship_between_dark_personality_traits_mental _toughness_resilience_and_character_strengths

Love, A. B., \& Holder, M. D. (2014). Psychopathy and subjective well-being. Personality and Individual Differences, 66, 112-117. https://doi.org/10.1016/.jpaid.2014.03.033

Lyons, M., Evans, K., \& Helle, S. (2019). Do "dark" personality features buffer against adversity? The associations between cumulative life stress, the dark triad, and mental distress. Sage open, 9(1), 1-13.

https://doi.org/10.1177/2158244018822383

Muris, P., Merckelbach, H., Otgaar, H., \& Meijer, E. (2017). The malevolent side of human nature: A meta-analysis and critical review of the literature on the dark triad (narcissism, Machiavellianism, and psychopathy).

Perspectives on Psychological Science, 12(2), 183-204.

https://doi.org/10.1177/1745691616666070

Nagy, H. \& Oláh, A. (2013). A pozitív pszichológia. Bányai É. \& Varga, K. (Eds.).

Affektív pszichológia - az emberi késztetések és érzelmek világa. (pp.

557-579.). Budapest: Medicina. 
Nagy, H. (2019). Pozitív pszichológia: Az elmélettől a gyakorlatig. Magyar Pszichológiai Szemle, 74(3), 289-299.

\section{https://doi.org/10.1556/0016.2019.74.3.2}

Nolen-Hoeksema, S. (2012). Emotion regulation and psychopathology: The role of gender. Annual review of clinical psychology, 8, 161-187. https://doi.org/10.1146/annurev-clinpsy-032511-143109

Oláh, A. (2005). Érzelmek, megküzdés és optimális élmény. Budapest: Trefort Kiadó. Retrieved October 14, 2021 from: https://mersz.hu/dokumentum/m858emoe__1/

Paulhus, D. L., \& Williams, K. M. (2002). The dark triad of personality: Narcissism, Machiavellianism, and psychopathy. Journal of research in personality, 36(6), 556-563. https://doi.org/10.1016/s0092-

\section{6(02)00505-6}

Petrides, K. V., Vernon, P. A., Schermer, J. A., \& Veselka, L. (2011). Trait emotional intelligence and the dark triad traits of personality. Twin Research and Human Genetics, 14(1), 35-41. https://doi.org/10.1375/twin.14.1.35

Pincus, A. L., \& Roche, M. J. (2011). Narcissistic grandiosity and narcissistic vulnerability. In W. K. Campbell \& J. D. Miller (Eds.), The handbook of narcissism and narcissistic personality disorder, Hoboken, NJ: Wiley, pp. $31-40$.

Saltoğlu, S., \& Irak, D. U. (2020). Primary versus secondary psychopathy: Coping styles as a mediator between psychopathy and well-being. Current Psychology, 1-9. https://doi.org/10.1007/s12144-020-01155-8

Shamsudheen, S. P., PD, B., \& Appu, A. V. (2017). A study of emotional maturity and self-control on Machiavellianism among office workers. Indian Journal of Health \& Well-being, 8(11), 1325-1334. Retrieved October 10, 2021 from: http://www.i-scholar.in/index.php/ijhw/article/view/165958

Shaver, P. R., Mikulincer, M., Baljinder, S., \& Gross, J. (2017). Attachment security as a foundation for kindness toward self and others. In K. W. Brown \& M. 
R. Leary (Eds.), The Oxford handbook of hypo-egoic phenomena. New York, NY: Oxford University Press.

https://doi.org/10.1093/oxfordhb/9780199328079.013.15

Smith, B. W., Dalen, J., Wiggins, K., Tooley, E., Christopher, P., \& Bernard, J. (2008).

The brief resilience scale: assessing the ability to bounce back. International journal of behavioral medicine, 15(3), 194-200.

https://doi.org/10.1080/10705500802222972

Szabó, E., \& Jones, D. N. (2019). Gender differences moderate Machiavellianism and impulsivity: Implications for Dark Triad research. Personality and Individual Differences, 141, 160-165.

https://doi.org/10.1016/j.paid.2019.01.008

Szabó, Z. P., Simon, E., Czibor, A., Restás, P., \& Bereczkei, T. (2021). The importance of dark personality traits in predicting workplace outcomes. Personality and Individual Differences, 183, 1-6.

https://doi.org/10.1016/j.paid.2021.111112

Van Groningen, A. J., Grawitch, M. J., Lavigne, K. N., \& Palmer, S. N. (2021). Every cloud has a silver lining: Narcissism's buffering impact on the relationship between the Dark Triad and well-being. Personality and Individual Differences, 171, 110549.

https://doi.org/10.1016/i.paid.2020.110549

Vargha, A., Zábó, V., Török, R. \& Oláh, A. (2020). A jóllét és a mentális egészség mérése: a Mentális Egészség Teszt. Mentálhigiéné és Pszichoszomatika, 21(3), 281-322.

https://doi.org/10.1556/0406.21.2020.014

Wastell, C., \& Booth, A. (2003). Machiavellianism: An alexithymic perspective. Journal of social and clinical psychology, 22(6), 730-744. https://doi.org/10.1521//iscp.22.6.730.22931

WHO, Retrieved October 23, 2021 from: https://www.who.int/news-room/factsheets/detail/mental-health-strengthening-our-response 